\title{
Analisis Konsumsi Daya Listrik Pada Kereta Penumpang Kelas Eksekutif Argo Cirebon (Studi Pada PT. Kereta Api Indonesia Daop 1 Jakarta)
}

\author{
${ }^{1}$ Raihan Afif Ruselando, ${ }^{2}$ Parjiman , ${ }^{3}$ Purwanto $\mathrm{G}$ \\ 1,2,3Pendidikan Teknik Elektro, Fakultas Teknik, Universitas Negeri Jakarta \\ 1,2,3Email: raihanafif30@gmail.com ; parjiman@unj.ac.id ; purwanto@unj.ac.id
}

\begin{abstract}
The purpose of this study is to conduct a study of the total electricity consumption on the Argo Cirebon executive class train, and to find out the number of passenger cars that can be added in accordance with the capacity of the generator in the generator wagon. The method used in this research is descriptive research method, to determine the electric power consumption on the trains that can be accommodated by the generator wagon. This research was conducted by measuring the needs of the wagon load, generator capacity, daily load, and calculating the maximum number of wagons that can be accommodated by the power wagon on the Argo Cirebon train while in Depo and during the Argo Cirebon train during Gambir-Cirebon PP trip. Based on the results of the study, it was found that, when the Argo Cirebon train was in the depot with a standard formation of $4 K 1+1 M 1+4 K 1+1 P$ series, the maximum current was $280 \mathrm{~A}$. The maximum load was $156 \mathrm{KW}$. Argo Cirebon KA in Gambir Journey - Cirebon (PP) with Standard Formation of $1 P+4 K 1+1 M 1+4 K 1+1$ Kl lux gen 2 series, maximum maximum load of $177 \mathrm{KW}$. The average current in the car is $35 \mathrm{~A}$. The capacity and percentage of the maximum power consumption of the train to the generator car $500 \mathrm{KVA}$ is $36.70 \%$ when the train is in the depot and $45.38 \%$ when the train is traveling Gambir-Cirebon PP. Power after improvement of power factor with capacitor reactive power rating of $105.96 \mathrm{KVAR}$, reactive power (Q2) $34.416 \mathrm{KVAR}$, active power becomes $176.6 \mathrm{KW}$ with apparent power $181.13 \mathrm{KVA}$ with Cos Phi 0.98. From the results of research that has been done, it is found that when the Argo Cirebon train is in the depot the power consumption is smaller than the Argo Cirebon train being on the trip, so that when traveling the maximum power consumption of the train to the generator set in the generator wagon is higher.
\end{abstract}

Keywords: power consumption, passenger train, metered Cirebon, voltage drop

\begin{abstract}
ABSTRAK
Tujuan dari penelitian ini adalah untuk melakukan penelitian tentang total konsumsi daya listrik pada Kereta kelas eksekutif Argo Cirebon, dan mengetahui jumlah gerbong penumpang yang dapat ditambah sesuai dengan kapasitas genset pada gerbong pembangkit. Metode yang digunakan dalam penelitian ini adalah metode penelitian deskriptif, untuk mengetahui konsumsi daya listrik pada kereta yang dapat ditampung oleh gerbong pembangkit Penelitian ini dilakukan dengan mengukur kebutuhan beban gerbong, kapasitas genset, beban harian, dan menghitung jumlah gerbong maksimum yang dapat ditampung oleh gerbong pembangkit pada kereta Argo Cirebon saat berada di Depo dan pada saat kereta Argo Cirebon selama perjalanan Gambir-Cirebon PP. Berdasarkan hasil penelitian diperoleh bahwa, saat kereta Argo Cirebon berada di Depo dengan Standar Formasi rangkaian $4 \mathrm{~K} 1+1 \mathrm{M} 1+4 \mathrm{~K} 1+1 \mathrm{P}$ arus maksimum sebesar $280 \mathrm{~A}$. Beban maksimum sebesar $156 \mathrm{KW}$, Setelah dihitung dan di analisis maka penambahan gerbong mampu sejumlah 10 gerbong. KA Argo Cirebon di Perjalanan Gambir - Cirebon (PP) dengan Standar Formasi rangkaian 1P + 4K1 + 1M1 + 4K1 + 1 K1 lux gen 2, beban maksimum maksimum $177 \mathrm{KW}$. Rata-rata arus pada gerbong sebesar 35 A. Kapasitas dan persentase konsumsi daya maksimum kereta terhadap gerbong pembangkit 500 KVA sebesar 36,70\% pada saat kereta berada di Depo dan 45,38 \% pada saat kereta melakukan perjalanan Gambir-Cirebon PP. Daya sesudah perbaikan faktor daya dengan rating daya reaktif kapasitor 105,96 KVAR, daya reaktif $\left(\mathrm{Q}_{2}\right) 34,416 \mathrm{KVAR}$, daya aktif menjadi 176,6 KW dengan daya semu 181,13 KVA dengan Cos Phi 0,98. Dari hasil penelitian yang telah dilakukan didapatkan bahwa pada saat KA Argo Cirebon berada di depo konsumsi daya lebih kecil dibandingkan KA Argo Cirebon berada di perjalanan, sehingga pada saat perjalanan konsumsi daya maksimum kereta terhadap genset di gerbong pembangkit lebih tinggi.
\end{abstract}

Kata Kunci: konsumsi daya, kereta penumpang, argo Cirebon, turun tegangan

\section{PENDAHULUAN}

Perkembangan teknologi transportasi meningkatkan persaingan antar perusahaan penyedia jasa transportasi. Tingkat kepuasan pelanggan menjadi salah satu tolak ukur keberhasilan perusahaan, termasuk pada PT.Kereta Api Indonesia (Persero) yang berstatus sebagai perusahaan milik negara (BUMN). PT.Kereta Api Indonesia (Persero) meningkatkan kepuasan pelanggan dengan menyediakan armada yang dilengkapi fasilitas penunjang sesuai dengan kelasnya, untuk meningkatkan kenyamanan dan memanjakan pelanggan. Penambahan fasilitas di Kereta 
tentunya akan menambah beban Kereta pembangkit, dimana Kereta pembangkit merupakan Kereta yang sangat vital dalam suatu rangkaian Kereta Api. Peningkatan fasilitas berupa air conditioner AC, TV, LCD, lampu, DVD, CCTV dan peralatan lainnya tentunya akan menambah kapasitas daya Kereta pembangkit. Berdasarkan hasil wawancara pada tanggal 12 Juli 2019 dengan Manager Produksi UPT Balai Yasa Manggarai, menyebutkan bahwa kapasitas genset yang dikeluarkan bisa jadi tidak sesuai dengan jumlah rangkaian kereta, sehingga perlu ada penyesuaian kapasitas genset untuk konsumsi daya listrik kereta. Pengamatan pada saat Kereta Argo Cirebon berada di perjalanan dilakukan peneliti pada tanggal 19 Januari 2020 yang dapat dilihat pada lampiran 7, melihat kapasitas genset yang ada kurang dimanfaatkan dan drop tegangan di paling ujung gerbong cukup besar sehingga mempengaruhi nilai beban listrik pada kereta Api. Sistem pendistribusian energi listrik pada kereta api harus handal dan harus mampu menyalurkan energi listrik sampai pada beban agar pelanggan dapat menikmati fasilitas yang ada tanpa ada gangguan.

${ }^{[1]}$ Berdasarkan penelitian analisis konsumsi daya listrik pada Kereta Api yang dilakukan pada tahun 2013 didapatkan bahwa pada kereta rute SemarangJakarta, yaitu: KA Argo Muria kelas eksekutif, KA Fajar dan Senja Utama kelas bisnis, dan KA Tawang Jaya kelas ekonomi untuk mengetahui beban maksimum gerbong penumpang, beban puncak maksimum, beban rata-rata harian, dan faktor kapasitas pemakaian genset kereta pembangkit. Beban maksimum terhitung K1 Argo Muria adalah 141,37kW, K2 Fajar dan Senja Utama adalah $20,74 \mathrm{~kW}$. Kapasitas dan persentase konsumsi daya maksimum kereta terhadap gerbong pembangkit untuk KM 500kVA sebesar $29,8 \%$, KMP2 150kVA sebesar 7,34\%, dan KMP3 50kVA sebesar 18,75\%. Berdasarkan dasar kondisi diatas, maka tujuan dari penulisan tugas akhir ini adalah menganalisa konsumsi daya listrik pada Kereta penumpang kelas eksekutif Argo Cirebon mengingat pada saat ini komponen kelistrikan pada kereta sudah berbeda, sehingga kelak Kereta pembangkit dirangkai dengan Kereta penumpang dalam jumlah yang lebih maksimal dan konsumsi daya listrik pada Kereta menjadi lebih efektif.
Hal ini akan menambah keuntungan perusahaan dan sangat bermanfaat ketika terjadi lonjakan penumpang luar biasa.

Berdasarkan latar belakang yang telah dipaparkan sebelumnya, dapat dijabarkan beberapa masalah yang dapat diidentifikasikan, yaitu beban maksimum dan beban rata-rata pada Kereta kurang diperhatikan sehingga gangguan penyaluran daya listrik dapat terjadi, kapasitas daya maksimum genset kurang dimanfaatkan dengan maksimal dalam hal memenuhi kebutuhan daya listrik Kereta pada saat terjadi lonjakan penumpang, Penambahan jumlah Kereta pada rangkaian Kereta tidak memperhatikan konsumsi daya listrik Kereta. Supaya hasil penelitian ini terarah dan tersistematis, peneliti perlu memberikan batasan masalah. Pembatasan ruang lingkup penelitian yaitu penelitian dilakukan di PT. Kereta Api Indonesia Daerah Operasional 1 (Daop) Jakarta, Penelitian dilakukan pada Kereta kelas Eksekutif Argo Cirebon jenis kereta K1 New Image tahun 2016, Penelitian dilakukan dengan kondisi kereta persiapan berangkat di Depo dan saat kereta dalam perjalanan Gambir-Cirebon PP, Penelitian dilakukan untuk mengukur beban rata-rata dan beban maksimum satu rangkaian Kereta api Argo Cirebon, agar dapat diketahui penambahan jumlah gerbong. Berdasarkan rumusan masalah yang sudah dijabarkan, tujuan yang ingin dicapai dari penelitian ini adalah untuk melakukan penelitian tentang total konsumsi daya listrik pada Kereta kelas eksekutif Argo Cirebon, dan mengetahui jumlah gerbong penumpang yang dapat ditambah sesuai dengan kapasitas genset pada gerbong pembangkit, maka penulis ingin melakukan penelitian yang berjudul "Analisis

Konsumsi Daya Listrik Pada Kereta Penumpang Kelas Eksekutif Argo Cirebon (Studi Pada PT.Kereta Api Indonesia Daop 1 Jakarta)".

\section{METODOLOGI PENELITIAN}

Penelitian tentang analisis konsumsi daya listrik pada kereta penumpang kelas eksekutif Argo Cirebon merupakan penelitian deskriptif guna mengetahui konsumsi daya listrik pada kereta yang dapat ditampung oleh gerbong pembangkit dengan menggunakan data dari hasil pengukuran berupa angka. Metode yang 
digunakan untuk penelitian ini adalah penelitian deskriptif. Metode penelitian deskriptif sebagai kegiatan yang meliputi pengumpulan data dalam rangka menguji hipotesis atau menjawab pertanyaan yang menyangkut keadaan yang sedang berjalan dari pokok suatu penelitian. Penelitian dilakukan dengan mengukur kebutuhan beban gerbong, kapasitas genset, beban harian, menghitung jumlah gerbong maksimum yang dapat ditampung oleh gerbong pembangkit, kemudian menganalisis data hasil pengukuran yang diperoleh dan mengambil kesimpulan tentang konsumsi daya listrik pada kereta Argo Cirebon yang dapat ditampung oleh gerbong pembangkit. ${ }^{[2]}$ Menurut Sugiyono (2016:137), metode pengumpulan data ialah cara atau strategi yang ditempuh untuk mengambil data dari varibel penelitian tersebut. Metode yang digunakan dalam penelitian ini adalah metode pengumpulan data observasi dan wawancara secara langsung di lapangan.

\section{HASIL DAN PEMBAHASAN}

\section{Kebutuhan Maksimum Gerbong K1 Kereta Argo Cirebon}

Berikut ini adalah data kebutuhan maksimum gerbong K1 Kereta Argo Cirebon yang dapat dilihat pada Tabel 1.

Tabel 1. Kebutuhan Maksimum Gerbong K1 KA Argo Cirebon

\begin{tabular}{|c|c|c|c|c|c|c|c|}
\hline \multirow{2}{*}{ Beban } & \multirow{2}{*}{$\begin{array}{l}\text { Tegangan } \\
\text { (I) }\end{array}$} & \multirow{2}{*}{$\begin{array}{c}\mathrm{PF} \\
\text { Cos?? }\end{array}$} & \multirow{2}{*}{$\begin{array}{c}\text { Jumbhh } \\
\text { Beban }\end{array}$} & \multirow{2}{*}{$\begin{array}{l}\text { Daya } \\
\text { (ii) }\end{array}$} & \multicolumn{2}{|c|}{ Daya Total } & \multirow{2}{*}{\begin{tabular}{|l|l} 
Alus \\
Ampere
\end{tabular}} \\
\hline & & & & & W & VA & \\
\hline Lampu IL 20W & 220 & 0,42 & 30 unit & 20 & 600 & 1428,57 & 6,493 \\
\hline Lampu Bagai & 220 & 0,42 & 28 unit & 40 & 392 & 933,33 & 4,242 \\
\hline LampuBaca & 220 & 0,8 & 50 unit & 45 & 150 & 187,5 & 0,852 \\
\hline Exknaust Fan & 220 & 0,8 & 2 unit & 18 & 36 & 45 & 0,203 \\
\hline $\mathrm{AC}$ & 380 & 0,6 & 2 unit & 7150 & 14300 & 23830 & 36,205 \\
\hline Televisi $L C D$ & 220 & 0,75 & 2urit & 100 & 200 & 266,66 & 1,212 \\
\hline Lampu Senboym & 220 & 1 & 10 unit & 14 & 140 & 140 & 0,636 \\
\hline \multirow[t]{2}{*}{ Stop Kontak } & 220 & 0,8 & 50 unit & & 2112 & 2640 & 12 \\
\hline & \multicolumn{2}{|c|}{ Total Teppassng } & & & 17930 & 294,71 & $\frac{61,844}{1}$ \\
\hline \multirow{2}{*}{ Betan } & \multirow{2}{*}{ 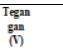 } & \multirow{2}{*}{ FF $\cos ?$} & \multirow{2}{*}{ 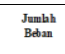 } & \multirow{2}{*}{$\begin{array}{l}\text { Daya } \\
\text { (ii) }\end{array}$} & \multicolumn{2}{|c|}{ Daya Total } & Arus \\
\hline & & & & & w & $\mathrm{vaA}$ & Amper. \\
\hline Lampu II 20W & 220 & 0,42 & 2 wit & 20 & 40 & 39,6 & 0,18 \\
\hline Lampu II to W & 220 & 0,42 & 10 mit & 40 & 400 & 398,2 & 1,81 \\
\hline TwoListili & 220 & 0.8 & 1 unt & 1500 & 1500 & 1498,2 & 6.81 \\
\hline LGroware & 220 & 0,65 & 1 wit & 2200 & 2200 & 22000 & 10 \\
\hline Show Care & 220 & 0,8 & 1 mint & 180 & 180 & 180,4 & 0,82 \\
\hline Freerer & 220 & 0,8 & 1 unit & 175 & 175 & 173,8 & 0,79 \\
\hline Inthent Fan & 220 & 0.8 & 5 wit & 18 & $\infty$ & 17,6 & 0,08 \\
\hline c & 330 & 0.6 & 1 wit & 9100 & 9100 & 9002,8 & 13,326 \\
\hline Teleriai LCD & 220 & 0,75 & 1 unit & 100 & 100 & 99,88 & 0,454 \\
\hline Lampu Semboran & 220 & 1 & 10urit & 14 & 140 & ${ }_{1 \pm 0}$ & 0,0003 \\
\hline & \multicolumn{2}{|c|}{ TonlTeppasn } & & & 1379 & 13839,48 & 348283 \\
\hline
\end{tabular}

Berdasarkan tabel kebutuhan maksimum gerbong K1 KA Argo Cirebon meliputi: lampu TL, lampu bagasi, lampu baca, exhaust fan, AC, televisi atau LCD, lampu semboyan, dan stop kontak.

\section{Data Pembebanan Genset pada KA Argo Cirebon di Depo}

Berikut ini ada data pembebanan genset pada KA Argo Cirebon pada saat berada di Depo yang dapat dilihat pada Tabel 2.

Tabel 2. Data Pembebanan Genset pada KA Argo Cirebon di Depo

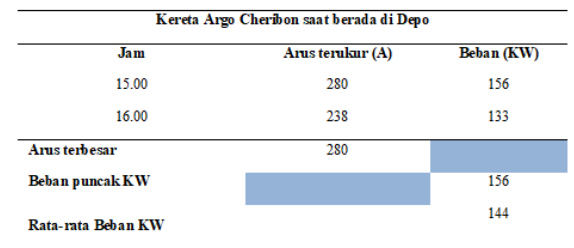

Berdasarkan tabel pembebanan genset berikut ini menjelaskan nilai arus dan beban pada KA Argo Cirebon saat berada di Depo, Pengukuran dilakukan pada pukul 15.00, 16.00. Data menunjukan nilai arus terukur dan beban yang terdapat pada panel genset, nilai arus yang turun ketika pukul 16.00 dikarenakan suhu pendinginan pada setiap gerbong telah tercapai begitu juga pada nilai beban yang turun ketika pukul 16.00 dikarenakan arus yang turun

Pengukuran Tegangan dan Arus pada KA Argo Cirebon di Depo

Berikut ini adalah data pengukuran Tegangan dan Arus pada KA Argo Cirebon saat di Depo yang dapat dilihat pada Tabel 3.

Tabel 3. Pengukuran Tegangan dan Arus pada KA Argo Cirebon di Depo

\begin{tabular}{|c|c|c|c|c|c|c|c|c|c|c|}
\hline \multirow{3}{*}{ No Gerbong } & \multirow{3}{*}{ SeriKereta } & \multirow{2}{*}{\multicolumn{3}{|c|}{ Tegangan (V) }} & \multirow{2}{*}{\multicolumn{3}{|c|}{$\begin{array}{c}\text { Tegangan (V) } \\
\text { L-N }\end{array}$}} & \multirow{2}{*}{\multicolumn{3}{|c|}{ Arus(A) }} \\
\hline & & & & & & & & & & \\
\hline & & RS & RT & ST & $\mathrm{RV}$ & SN & $\mathrm{TN}$ & IR & IS & IT \\
\hline 1. & K1 01707 & 379 & 378 & 379 & 218 & 217 & 218 & 34 & 33 & 34 \\
\hline 2. & K1 10108 & 379 & 378 & 379 & 218 & 217 & 217 & 33 & 34 & 34 \\
\hline 3. & K1 01703 & 378 & 377 & 378 & 218 & 217 & 218 & 33 & 33 & 33 \\
\hline 4. & K1 101704 & 378 & 376 & 377 & 218 & 216 & 218 & 33 & 33 & 34 \\
\hline 5. & M1 01701 & 378 & 377 & 376 & 218 & 217 & 218 & 7.7 & 7,8 & 7,8 \\
\hline 6. & K1 01702 & 378 & 376 & 377 & 218 & 216 & 217 & 34 & 34 & 33 \\
\hline 7. & K1 101666 & 375 & 374 & 376 & 218 & 216 & 217 & ${ }_{33}$ & 33 & 34 \\
\hline 8. & K1 01667 & 374 & 374 & 375 & 216 & 214 & 217 & 33 & 33 & 33 \\
\hline 9. & K1 101668 & 371 & 370 & 372 & 215 & 212 & 216 & 34 & 33 & 34 \\
\hline
\end{tabular}

Berdasarkan tabel pengukuran tegangan dan arus grafik nilai arus pada saat KA Argo Cirebon berada di Depo dari gerbong 1 hingga 9 menunjukan nilai rentang antara 33 hingga 34 A. Pada gerbong makan arus terukur $7.8 \mathrm{~A}$ karena peralatan listrik pada gerbong makan tidak sedang digunakan, setelah melakukan pengukuran dari gerbong paling depan hingga belakang maka hasil pengukuran menunjukan bahwa semakin jauh gerbong dari pembangkit maka nilai tegangan semakin turun. Hasil pengukuran menunjukan saat gerbong dibebani penuh. Nilai arus pada gerbong kereta makan kecil karena hanya menggunakan satu AC 
sedangkan gerbong penumpang 2 AC. Selain itu peralatan seperti kulkas, frezzer, microwave, teko listrik dalam keadaan mati.

\section{Pembebanan Genset pada KA Argo Cirebon di Perjalanan}

Berikut ini adalah data pembebanan genset pada KA Argo Cirebon di Perjalanan yang dapat dilihat pada Tabel 4.

Tabel 4. Pembebanan Genset pada KA Argo

\begin{tabular}{|c|c|c|c|}
\hline \multicolumn{4}{|c|}{ 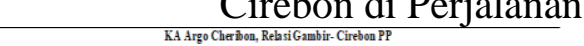 } \\
\hline \multirow{7}{*}{ P 00902} & $\mathrm{~J}_{\mathrm{m} \mathrm{m}}$ & Arus (A) & Beban (KiT) \\
\hline & 0730 & 297 & 153 \\
\hline & 0830 & 229 & 116 \\
\hline & 0930 & 254 & 126 \\
\hline & 1030 & 344 & 177 \\
\hline & 1200 & 315 & 157 \\
\hline & 1330 & 296 & 152 \\
\hline Aras Terbess (A) & & 34 & \\
\hline Beban Puncak(KW) & & & 177 \\
\hline
\end{tabular}

Berdasarkan tabel pembebanan genset pada KA Argo Cirebon di Perjalanan hasil pengukuran pembebanan pada genset menunjukan bahwa pada saat perjalanan Gambir - Cirebon nilai arus cenderung kecil karena beban AC yang diatur hanya $1 \mathrm{AC}$ saja tidak 2 AC pertimbangan nya karena cahaya matahari belum panas. Sedangkan dari arah Cirebon - Gambir nilai arus cenderung besar. Terlihat dari pukul 10.30 nilai arus $344 \mathrm{~A}$ karena baru saja AC di posisikan ke 2 AC pada setiap gerbongnya, hingga pada akhirnya nilai arus cenderung turun karena suhu pendinginan mulai stabil.

\section{Pengukuran Tegangan dan Arus pada KA Argo Cirebon di Perjalanan}

Berikut ini adalah data pengukuran Tegangan dan Arus pada KA Argo Cirebon saat di Perjalanan yang dapat dilihat pada Tabel 5.

Tabel 5. Pengukuran Tegangan dan Arus pada

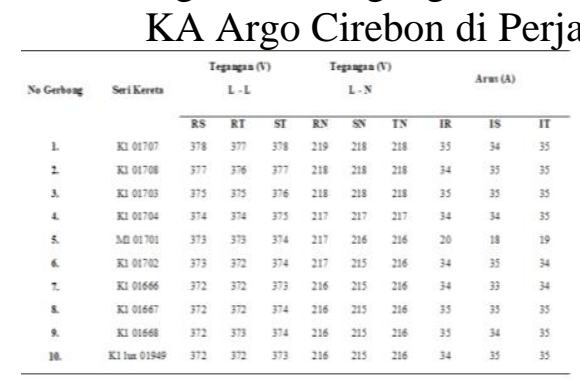

Berdasarkan grafik Arus terlihat bahwa nilai arus pada gerbong $7,8,9$, dan 10 cenderung turun, hal ini dikarenakan suhu pendinginan pada gerbong tersebut sudah tercapai sehingga AC tidak bekerja secara penuh dan otomatis mempengaruhi besarnya nilai arus. Pada grafik tegangan terlihat bahwa dari gerbong paling depan hingga belakang menunjukan bahwa semakin jauh gerbong dari pembangkit maka nilai tegangan semakin turun.

\section{Perbandingan Beban Terpasang pada KA Argo Cirebon}

Berikut ini adalah data perbandingan beban terpasang pada KA Argo Cirebon yang dapat dilihat pada Tabel 6.

Tabel 6. Perbandingan Beban Terpasang pada

\begin{tabular}{|c|c|c|}
\hline \multicolumn{3}{|c|}{ KA Argo Cirebon } \\
\hline & $\overline{D p p o}$ & Gambir- Cirtebon PP \\
\hline Daya Aktef Maiksimum & $190 \mathrm{KVA}$ & $226 \mathrm{KVA}$ \\
\hline Daya Akbf Ratar-sta & $169 \mathrm{KVA}$ & $187 \mathrm{KV} A$ \\
\hline Faktor Kapasistas & 0,38 & 0,37 \\
\hline
\end{tabular}

Berdasarkan tabel perbandingan beban terpasang pada KA Argo Cirebon terlihat bahwa daya aktif maksimum dan daya aktif rata-rata pada KA Argo Cirebon yang berada di depo lebih besar dibandingkan KA Argo Cirebon yang berada di perjalanan, hal ini dikarenakan pada saat kereta berada di depo belum ada penumpang dan pemakaian beban belum maksimal sedangkan dalam perjalanan KA Argo Cirebon dalam kondisi ada penumpang dan peralatan pada kereta restorasi sudah digunakan selain itu daya aktif cenderung fluktuatif karena kondisi perjalanan dari waktu pagi ke siang hari mempengaruhi suhu pendinginan gerbong dan gerbong sehingga AC tidak bekerja penuh terus menerus.

\section{Perbandingan Kapasitas Generator pada KA Argo Cirebon}

Berikut ini adalah data perbandingan kapasitas generator pada KA Argo Cirebon yang dapat dilihat pada Tabel 7.

Tabel 7. Perbandingan Kapasitas Generator

\begin{tabular}{|c|c|c|}
\hline \multicolumn{3}{|c|}{ Kapasihs Generator KA Argo Cheribon } \\
\hline & Depo & Gambir - Cirboon PP \\
\hline Kapasitas Genenator & $36,70 \%$ & $45,38 \%$ \\
\hline
\end{tabular}

Berdasarkan tabel perbandingan kapasitas generator pada KA Argo Cirebon terlihat bahwa kapasitas genetaror pada KA Argo Cirebon di perjalanan lebih tinggi dari total daya aktif genset $500 \mathrm{KVA}$, hal ini karena pada saat dalam perjalanan beban puncak terukur $177 \mathrm{KW}$ dan yang mempengaruhinya adalah suhu pendinginan dalam gerbong yang tercapainya fluktuatif selama perjalanan, serta gerbong restorasi yang sudah digunakan. Sedangkan lain halnya dengan kapasitas 
generator pada saat kereta di Depo yang penggunaan beban belum maksimal. Melihat kapasitas generator pada saat KA Argo Cirebon dalam perjalanan baru $45,38 \%$, sebaiknya kapasitas genset yang digunakan pada kereta disesesuaikan dengan jumlah beban.

\section{Turun Tegangan pada KA Argo Cirebon}

Berikut ini adalah data turun tegangan pada KA Argo Cirebon yang dapat dilihat pada Tabel 8.

Tabel 8. Turun Tegangan pada KA Argo

\begin{tabular}{|c|c|c|c|}
\hline & \multicolumn{3}{|c|}{ Cirebon } \\
\hline No.Gerbong & No. Serie & ?m(V) & $\% ? n$ \\
\hline 1. & K1 01707 & 0,160 & 0,04 \\
\hline 2. & K1 01708 & 0,311 & 0,08 \\
\hline 3. & K1 101703 & 0,467 & 0,12 \\
\hline 4. & K1 01704 & 0,622 & 0,16 \\
\hline 5. & M1 01701 & 0,183 & 0,04 \\
\hline 6. & K1 01702 & 0,962 & 0,25 \\
\hline 7. & K1 01666 & 1,089 & 0,28 \\
\hline 8. & K1 01667 & 1,245 & 0,33 \\
\hline 9. & K1 01668 & 1,443 & 0,37 \\
\hline
\end{tabular}

Berdasarkan tabel turun tegangan terlihat bahwa dari gerbong paling depan hingga belakang menunjukan bahwa semakin jauh gerbong dari pembangkit maka nilai turun tegangan akan semakin besar dan menunjukan persentase turun tegangan di gerbong paling akhir sebesar $0,39 \%$. Perbedaan turun tegangan pada saat KA Argo Cirebon berada di depo dan pada saat perjalanan sangat terlihat pada gerbong 5 yaitu gerbong restorasi, dengan nilai turun tegangan pada saat di depo 0,183 V dikarenakan penggunaan arus yang kecil dan pada saat perjalanan nilai turun tegangan 0,433 $\mathrm{V}$, naiknya nilai turun tegangan pada saat di perjalanan dikarenakan besarnya penggunaan arus di gerbong restorasi.

\section{Perbaikan Faktor Daya}

Berikut ini adalah data perbaikan faktor daya pada KA Argo Cirebon yang dapat dilihat pada Tabel 9.

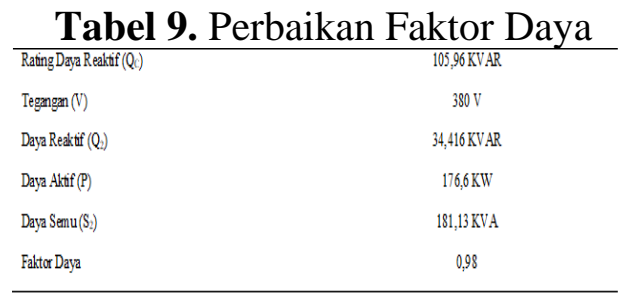

Berdasarkan tabel perbaikan faktor daya rating daya reaktif $\left(\mathrm{Q}_{\mathrm{C}}\right)$ adalah 105,96 KVAR. Daya reaktif $\left(\mathrm{Q}_{2}\right) 34,416 \mathrm{KVAR}$, Daya Aktif (P) 176,6 KW, Daya Semu $\left(S_{2}\right)$ 181,13 KVA, dengan rekomendasi nilai faktor daya 0,98 .

\section{Kesimpulan dan Saran \\ Kesimpulan}

Pada penelitian analisis konsumsi daya listrik yang dilakukan pada Kereta Argo Cirebon saat sedang berada di Depo sebelum keberangkatan menuju Cirebon dan saat sedang dalam perjalanan Gambir - Cirebon (PP).

Pada saat KA Argo Cirebon berada di Depo dilakukan pada 22 Desember 2019, KA Argo Cirebon dengan Standar Formasi rangkaian $4 \mathrm{~K} 1+1 \mathrm{M} 1+4 \mathrm{~K} 1+1 \mathrm{P}$. Konsumsi daya listrik pada KA Argo Cirebon dapat dikatakan baik dengan hasil arus maksimum sebesar 280 A. Faktor daya didapatkan dari Deep Sea Electronic sebesar 0,85 lg, kapasitas daya genset yang digunakan $36,70 \%$. Setelah dihitung dan di analisa maka penambahan gerbong mampu sejumlah 10 gerbong.

Pengukuran pada saat KA Argo Cirebon di Perjalanan Gambir - Cirebon (PP) dilakukan pada 19 Januari 2020, KA Argo Cirebon sudah melakukan penambahan satu buah gerbong dengan Standar Formasi rangkaian $1 \mathrm{P}+4 \mathrm{~K} 1+$ $1 \mathrm{M} 1+4 \mathrm{~K} 1+1 \mathrm{~K} 1$ lux gen 2 . Konsumsi daya listrik pada KA Argo Cirebon di perjalanan dapat dikatakan kurang baik dengan hasil arus maksimum sebesar 344 A. Faktor daya didapatkan dari Deep Sea Electronic sebesar $0,78 \mathrm{lg}$, kapasitas daya genset yang digunakan sebesar 45,38\%. Kapasitas daya genset kurang dimanfaatkan dengan baik, jika menambah gerbong terdapat masalah pada nilai drop tegangan yang besar sehingga harus memperbaiki faktor daya dengan pemasangan kapasitor.

Pada KA Argo Cirebon untuk memperbaiki faktor daya dilakukan pengukuran pada saat KA Argo Cirebon dalam perjalanan, dengan cos phi 0,78 menjadi 0,98 dibutuhkan kapasitor dengan daya reaktif $105,96 \mathrm{KVAR}$.

\section{Saran}

Penelitian konsumsi daya listrik dilakukan pada KA Argo Cirebon saat berada di Depo dan sedang dalam perjalanan Gambir - Cirebon (PP), selama penelitian berlangsung ditemukan bahwa drop tegangan pada KA Argo Cirebon di gerbong ujung cukup tinggi, hal ini perlu di perhatikan oleh operator perkeretaapian untuk memperbaiki kualitas daya agar efisiensi dapat tercapai. Selain itu nilai faktor daya pada genset P 00902 jauh dari kata normal, maka perlu 
dilakukan perbaikan kualitas daya agar menghasilkan daya aktif yang lebih besar untuk penggunaan gerbong yang lebih banyak ketika terjadi lonjakan penumpang. Penelitian ini memiliki keterbatasan keterkaitan dengan kelas kereta, karena keterbatasan waktu peneliti. Penelitian selanjutnya disarankan untuk melakukan penelitian pada setiap kelas kereta atau jenis kelas kereta campuran dalam satu rangkaian, hal tersebut menarik untuk diteliti karena setiap kelas kereta dan tahun pembuatan mempengaruhi kualitas daya listrik pada rangkaian kereta.

\section{DAFTAR PUSTAKA}

[1] Arfianto, Muhammad, Rizal. (2013). Analisis Konsumsi Daya pada Kereta Penumpang. Jurnal Universitas Diponegoro. 2:1-8

[2] Sugiyono. (2016). Metode Penelitian Kuantitatif, Kualitatif, dan $R \& D$. Bandung : Alfabeta

[3] Hakim, Muhammad, Fahmi. (2014). Analisis Kebutuhan Capacitor Bank Beserta Implementasinya Untuk

[4] Memperbaiki Faktor Daya Listrik Di Politeknik Kota Malang. Politeknik Kota Malang, Vol 12 No.1 April 2014.

[5] Rahardjo ; Yunus, Yadi. (2010). Perbaikan Faktor Daya Motor Induksi 3 Fase. Sekolah Tinggi Teknologi Nuklir, ISSN 19780176

[6] Rusda.; Karim, Khairuddin ; Masing. Politeknik Negeri Samarinda. Analisis Perbaikan Faktor Daya Untuk Penghematan Energi Listrik Pada Politeknik Negeri Samarinda. [Prosiding] Seminar Nasional Teknologi IV ; Samarinda, 9 November 2017. Samarinda. Universitas Mulawarman 